\title{
Endometrial Assessment: When is it Necessary?
}

\author{
Juliana Nicoletti Pessoa ${ }^{\mathrm{a}}$, Ana Carolina Lopes Freitas ${ }^{\mathrm{a}}$, Ronney Antonio Guimaraes ${ }^{\mathrm{a}}$, \\ Jonnymar Lima ${ }^{\mathrm{a}}$, Helena Lucia Barroso dos Reis ${ }^{\mathrm{b}, \mathrm{c}}$, Antonio Chambo Filho ${ }^{\mathrm{a}}$
}

\begin{abstract}
Background: Endometrial cancer is the fourth most common cancer among women and the most common malignant neoplasm of the female genital tract in the USA. The onset is usually after the age of 50 and prognosis depends on the stage of disease at diagnosis. We aimed at determining the prevalence of high-risk endometrial lesions in women of different ages to establish a protocol for the indication of invasive diagnostic procedures.
\end{abstract}

Methods: A retrospective study was conducted based on the descriptive and statistical analysis of histopathological records of 2,931 patients who underwent uterine curettage between January 2001 and December 2011 at our institution.

Results: The risk of endometrial malignancy was about 10 times higher in patients aged 50 years or older than that in younger women. However, women with abnormal uterine bleeding had a higher prevalence of high-risk conditions, regardless of age.

Conclusion: Atypical and complex endometrial hyperplasia and carcinoma can affect women of all ages, but are more common in patients 50 years of age or older. Thus, endometrial sampling is recommended as a routine procedure for all women 50 years of age or older with clinical indications of the disease and as a screening procedure for those undergoing hysterectomy.

Keywords: Neoplasms; Endometrium; Age groups; Prevalence; Uterine hemorrhage; Risk factors; Carcinoma; Curettage; Ultrasonography; Endometrial hyperplasia

\footnotetext{
Manuscript accepted for publication November 19, 2013

${ }^{a}$ Gynecology and Obstetrics Department, Santa Casa de Misericordia School of Science, Brazil

${ }^{\mathrm{b}}$ Gynecology and Obstetrics Department, Espirito Santo Federal

University, Brazil

${ }^{\mathrm{c} C o r r e s p o n d i n g ~ a u t h o r: ~ H e l e n a ~ L u c i a ~ B a r r o s o ~ d o s ~ R e i s, ~ G y n e c o l o g y ~}$ and Obstetrics Department, Espirito Santo Federal University, Brazil. Email: hbarroso@intervip.com.br
}

doi: http://dx.doi.org/10.4021/jocmr1684w

\section{Introduction}

Endometrial cancer is the fourth most common cancer among women and the most common malignant neoplasm of the female genital tract in the USA [1]. According to the Brazilian National Cancer Institute (INCA), the most common neoplasms among women in Brazil include non-melanoma skin tumors, tumors of the breast, cervix, colon and rectum, and lung and, less frequently, endometrial cancer [2]. Prognosis of endometrial cancer varies from excellent to very poor, depending on the stage of the disease at diagnosis [3]. The incidence of endometrial cancer has increased in the past decade although the incidence and mortality rates of other types of cancer have stabilized or even decreased. The increased incidence of endometrial cancer may be due to a rise in the diagnosis of advanced-stage cancers and in the incidence of histological subtypes of endometrial cancer with poor prognosis $[1,4]$.

Endometrial cancer affects predominantly women aged between 50 and 60 years, but $20-25 \%$ of cases are diagnosed in premenopausal women $[5,6]$. The most common symptom in pre- and postmenopausal women is abnormal uterine bleeding, which is present in $90 \%$ of patients with endometrial cancer. Women with abnormal uterine bleeding should be tested because $10 \%$ of cases among postmenopausal women are caused by endometrial cancer [7]. Transvaginal sonography is an important tool for detecting endometrial disease in postmenopausal women with abnormal uterine bleeding, when the endometrial thickness is $\leq 4 \mathrm{~mm}[8,9]$. Few studies have performed routine endometrial sampling in asymptomatic women because of the invasiveness of the procedure. These studies have estimated prevalences of simple and complex hyperplasias ranging from 0.5 to $5 \%$ and prevalences of atypical hyperplasia and carcinoma to be $<1 \%[10,11]$. The American Cancer Society does not recommend routine screening for endometrial cancer in asymptomatic women [8], and the Canadian Cancer Society reported that routine transvaginal sonography or endometrial sampling does not result in lower mortality rates of endometrial cancer [8].

According to the terminology adopted by the World 
Table 1. Histopathological Findings

\begin{tabular}{lll}
\hline Histopathological findings & $\mathbf{N}$ & $\mathbf{\%}$ \\
\hline Insufficient material & 195 & 6.74 \\
Endometrial atrophy & 102 & 3.53 \\
Polyps & 980 & 33.87 \\
Other benign changes & 1,302 & 45.00 \\
Simple hyperplasias without atypia & 200 & 6.91 \\
Simple hyperplasias with atypia & 13 & 0.45 \\
Complex hyperplasias & 19 & 0.66 \\
Endometrial cancer & 82 & 2.83 \\
Total & 2,893 & 100 \\
\hline
\end{tabular}

Health Organization (WHO), the severity of endometrial hyperplasia is classified as simple or complex based on architectural features, and as typical or atypical based on cytologic features, as initially described by Kurman et al [12]. Atypical hyperplasia is considered a precursor lesion, which may progress to endometrial cancer in 5\% to $25 \%$ of patients $[13,14]$. Some studies have reported that atypical hyperplasia may coexist with endometrial cancer. Histopathological examination of hysterectomy specimens revealed that $20 \%$ to $43 \%$ of patients previously diagnosed with endometrial atypical hyperplasia by biopsy also had endometrial cancer [13-16].

About $80 \%$ of endometrial cancers are histologically classified as type I endometrioid carcinomas with minimal myometrial invasion, arising from atypical complex hyperplasia, and especially affecting pre- and perimenopausal women. Type I endometrioid carcinomas are usually estrogen-receptor-positive tumors associated with hyperestrogenism and prior estrogenic stimulation. Several statistical studies have indicated a positive association of endometrial hyperplasia with obesity, diabetes, high blood pressure, breast cancer, chronic anovulation, estrogen-producing ovarian tumors, and genetic predisposition [10, 11, 14]. In contrast, type II endometrial cancers occur mostly in elderly or postmenopausal non-obese women, are more aggressive, have poor prognosis, and are frequently not associated with high estrogen levels [7, 14]. Because endometrial hyperplasia precedes the development of endometrial cancer by up to 10 years, the early diagnosis and treatment of this condition could significantly reduce the number of new cases of endometrial cancer [17].

Given the importance of the topic, the aim of this study was to estimate the current prevalence of high-risk endometrial lesions in women of different ages in the study institution to determine the cut-off age for indication of endometrial sampling as a screening procedure for endometrial cancer. This information makes it possible to focus on the endometrial screening of patients in high-risk groups and decrease the number of invasive procedures in low-risk groups, reducing health care costs and the risk of morbidity associated with invasive diagnostic procedures.

\section{Materials and Methods}

The study was approved by the Research Ethics Committee of the Santa Casa de Misericordia School of Science of Vitoria, Brazil (approval number 039/2011) and was conducted in full accordance with ethical principles, including the World Medical Association Declaration of Helsinki (59th WMA General Assembly, Seoul, October 2008) [18]. Patient anonymity was ensured.

This was a retrospective study based on the descriptive and statistical analysis of data obtained from medical records of patients who were treated between January 2001 and December 2011 at the Obstetrics and Gynecology and Pathology Services of the Santa Casa de Misericordia School of Science Hospital.

The medical records of 2,931 patients who underwent uterine curettage were reviewed and the parameters: histopathological findings, age, and clinical indications were recorded. Thirty-eight of these patients were excluded for incomplete records, leaving 2,893 cases for the analysis. All endometrial curettage samples were collected at the obstet- 
Table 2. Correlation Between Endometrial Malignancy and the Presence or Absence of Uterine Bleeding

\begin{tabular}{llllll}
\hline $\begin{array}{l}\text { Uterine } \\
\text { bleeding }\end{array}$ & Benign lesion & $\%$ & $\begin{array}{l}\text { Malignant } \\
\text { lesion }\end{array}$ & \% & Total \\
\hline Present & 983 & 93.44 & 69 & 6.56 & 1,052 \\
Absent & 1,796 & 97.55 & 45 & 2.45 & 1,841 \\
Total & 2,779 & 96.06 & 114 & 3.94 & 2,893 \\
\hline
\end{tabular}

rics and gynecology service by different examiners and analyzed by clinical pathologists of the pathology service of the same institution.

The histopathological findings were classified according to the WHO classification as simple or complex hyperplasia, typical or atypical hyperplasia, and endometrial cancer, including all histological subtypes [12].

The subjects were stratified by age ( $\leq 29$ years; 30 - 49 years; and $\geq 50$ years), clinical indications, and presence or absence of uterine bleeding.

Statistical analysis was carried out using the Statistical Package for the Social Sciences (SPSS) 11.5 for Windows (SPSS Inc., Chicago, IL, USA). Risk of endometrial malignancy was estimated using odds ratio (OR) with a 95\% confidence interval (CI). The chi-square test was used to test for association between uterine bleeding (presence or absence) and histopathological findings (benign or malignant endometrial disease). All statistical tests were performed at a significance level of $0.05(\mathrm{P}<0.05)$.

\section{Results}

The clinical indications among the 2,893 patients who underwent uterine curettage were uterine bleeding alone $(\mathrm{n}=$ $795)$, and uterine bleeding combined with polyps $(\mathrm{n}=747)$, myoma $(n=323)$, endometrial thickening $(n=695)$, or other minor problems. Abnormal uterine bleeding was present in $36.39 \%$ of patients, while $63.61 \%$ of patients had no pathological bleeding.

Histopathological examination revealed 2,779 benign endometrial lesions, of which the most common were endometrial atrophy, polyps, and simple endometrial hyperplasia without atypia, as well as other benign changes including dysfunctional and proliferative endometrium. One hundred and fourteen histopathological findings were suspicious for malignancy, 13 were simple endometrial hyperplasias with atypia, 19 were complex hyperplasias, and 82 were endometrial cancers including the different histological subtypes (Table 1).

For patients with abnormal uterine bleeding, 983 histo- pathological findings were benign and 69 were malignant, while for patients who had no bleeding, 1,796 findings were benign and 45 were malignant (Table 2 ). There was a significant association of uterine bleeding with the presence of endometrial malignancy $(\mathrm{P}<0.05)$.

According to age group, it was found that 122 of 124 histopathological findings were benign and only 2 were malignant for patients aged $\leq 29$ years; 1,755 findings were benign and 16 malignant for patients 30 - 49 years old, and 902 findings were benign and 96 malignant for patients aged $\geq$ 50 years (Table 3 ).

Patients aged $\geq 50$ years had a higher risk of endometrial malignancy than patients aged $\leq 29$ years $(\mathrm{OR}=6.49 ; 95 \%$ $\mathrm{CI}=1.55-38.54 ; \mathrm{P}<0.01)$ and those aged $30-49$ years $(\mathrm{OR}$ $=11.67 ; 95 \% \mathrm{CI}=6.67-20.71 ; \mathrm{P}<0.01)$. The relative risk of endometrial malignancy for patients $\geq 50$ years of age was 1.09 when compared with those $\leq 29$ years of age and 1.10 when compared with those aged $30-49$ years.

\section{Discussion}

Endometrial cancer is the fourth most common cancer in women in the USA. It is estimated that 34,000 new cases of endometrial cancer were diagnosed and 6,000 deaths were caused by endometrial cancer in 1996 in the USA, with incidences ranging from 12/100,000/year in women aged $\leq 40$ years to $100 / 100,000 /$ year in women aged $\geq 60$ years [19]. In Brazil, it is estimated that 5,685 new cases of endometrial adenocarcinoma occur annually, with a mean incidence of $7.6 / 100,000 /$ year, ranging from $2 / 100,000 /$ year in the Northern Region of the country to $9.9 / 100,000 /$ year in the Southwest Region [2].

Our results revealed an overall incidence of endometrial cancer of $2.83 \%$, which rises to about $4 \%$ if precursor lesions for malignancy are included. These estimated incidences are much higher than those reported for the general population, because in this study we evaluated data from a specific population seen at a tertiary hospital and who were presenting symptoms of endometrial cancer or clinical indications for endometrial screening. However, our results by age group 
Table 3. Uterine Malignancy by Age Group

\begin{tabular}{llllll}
\hline $\begin{array}{l}\text { Age group } \\
\text { (years) }\end{array}$ & Benign lesion & $\%$ & $\begin{array}{l}\text { Malignant } \\
\text { lesion }\end{array}$ & \% & Total \\
\hline$\leq 29$ & 122 & 98.39 & 2 & 1.61 & 124 \\
$30-49$ & 1,755 & 99.10 & 16 & 0.90 & 1,771 \\
$\geq 50$ & 902 & 90.38 & 96 & 9.62 & 998 \\
Total & 2,779 & 96.06 & 114 & 3.94 & 2,893 \\
\hline
\end{tabular}

are consistent with those reported for the general population, in which the incidence of endometrial malignancy increases for patients aged $\geq 50$ years (Table 3 ).

We observed that patients aged $\geq 50$ years had a higher risk of endometrial malignancy than patients aged $\leq 29$ years $(\mathrm{OR}=6.49 ; 95 \% \mathrm{CI}=1.55-38.54 ; \mathrm{P}<0.01)$ and those aged $30-49$ years $(\mathrm{OR}=11.67 ; 95 \% \mathrm{CI}=6.67-20.71 ; \mathrm{P}$ $<0.01)$. The relative risk of endometrial malignancy for patients aged $\geq 50$ years was 1.09 when compared with those aged $\leq 29$ years and 1.10 when compared with those aged 30 - 49 years. This shows that the risk of endometrial cancer in women 50 years of age or older is about 10 times higher than that in younger women and indicates the importance of endometrial sampling for this age group.

Iram et al [20] conducted a study with 3,006 premenopausal women with abnormal uterine bleeding and reported prevalences of hyperplasia and carcinoma significantly higher in women aged 45 - 50 years than in younger women. The authors suggested a cut-off age of 45 years for endometrial sampling in patients with abnormal uterine bleeding. Our results revealed prevalences of malignant endometrial disease of $6.56 \%$ in patients with uterine bleeding, and of $2.45 \%$ in patients who had no uterine bleeding, with a significant association of uterine bleeding with the presence of endometrial malignancy $(\mathrm{P}<0.05)$. Irregular menstrual bleeding has always been considered a warning sign and a high-risk factor for malignancy. Crissman et al [17] carried out a study with 54 endometrial cancer patients aged $\leq 40$ years, and reported that $81 \%$ of patients presented with irregular menstrual bleeding [20]. Similar findings have been reported more recently by Iram et al [20], who observed that 22 of 23 endometrial cancer patients aged $\leq 45$ years had irregular menstrual bleeding.

Atypical or complex endometrial hyperplasia and endometrial cancer can affect women in any age group, but are more common among those aged 50 years or older. Based on our results, we recommend endometrial sampling for all women aged $\geq 50$ years who have clinical indications of endometrial malignancy, and, occasionally, for those undergoing hysterectomy regardless of whether they are pre- or postmenopausal. On the other hand, invasive diagnostic procedures are not indicated for asymptomatic women younger than 50 years because patients at this age group were found to be at statistically low-risk for endometrial cancer development. Endometrial sampling in younger women increases health care costs and the risk of morbidity associated with invasive diagnostic procedures. However, premenopausal women with irregular menstrual bleeding should also undergo endometrial sampling, because this symptom is highly associated with endometrial malignancy.

The data analyzed in this retrospective study was extracted from hospital records; hence, it was impossible to provide information on underlying diseases.

\section{Disclosure Statement}

The authors have no conflicts of interest to disclose.

\section{Disclosure of Funding}

There was no external funding for this study.

\section{References}

1. Jemal A, Murray T, Ward E, Samuels A, Tiwari RC, Ghafoor A, Feuer EJ, et al. Cancer statistics, 2005. CA Cancer J Clin. 2005;55(1):10-30.

2. Brazil, Ministerio da Saude: Estimativa 2012 - Incidencia de cancer no Brasil [Estimate/2012 - Cancer Incidence in Brazil]. Rio de Janeiro, INCA, 2011. Retrieved August 16, 2012 from: http:/www.inca.gov.br/estimativa/2012/estimativa20122111.pdf.

3. Zhang Y, Wang J. Controversies in the management of endometrial carcinoma. Obstet Gynecol Int. 2010;2010:862908.

4. Boruta DM, 2nd, Gehrig PA, Fader AN, Olawaiye AB. Management of women with uterine papillary serous 
cancer: a Society of Gynecologic Oncology (SGO) review. Gynecol Oncol. 2009;115(1):142-153.

5. Brand A, Duduc-Lissoir J, Ehlen TG, Plante M. Diagnosis of endometrial cancer in women with abnormal vaginal bleeding. J Soc Obstet Gynaecol Can. 2000;22:102104.

6. National Cancer Institute of Canada: Canadian Cancer Statistics 2012. Toronto, Canada 2012.

7. Bakkum-Gamez JN, Gonzalez-Bosquet J, Laack NN, Mariani A, Dowdy SC. Current issues in the management of endometrial cancer. Mayo Clin Proc. 2008;83(1):97112.

8. Gupta JK, Chien PF, Voit D, Clark TJ, Khan KS. Ultrasonographic endometrial thickness for diagnosing endometrial pathology in women with postmenopausal bleeding: a meta-analysis. Acta Obstet Gynecol Scand. 2002;81(9):799-816.

9. Tabor A, Watt HC, Wald NJ. Endometrial thickness as a test for endometrial cancer in women with postmenopausal vaginal bleeding. Obstet Gynecol. 2002;99(4):663-670.

10. Gol K, Saracoglu F, Ekici A, Sahin I. Endometrial patterns and endocrinologic characteristics of asymptomatic menopausal women. Gynecol Endocrinol. 2001;15(1):63-67.

11. Korhonen MO, Symons JP, Hyde BM, Rowan JP, Wilborn WH. Histologic classification and pathologic findings for endometrial biopsy specimens obtained from 2964 perimenopausal and postmenopausal women undergoing screening for continuous hormones as replacement therapy (CHART 2 Study). Am J Obstet Gynecol. 1997;176(2):377-380.

12. Kurman RJ, Kaminski PF, Norris HJ. The behavior of endometrial hyperplasia. A long-term study of "untreated" hyperplasia in 170 patients. Cancer. 1985;56(2):403412.

13. Creasman WT. Endometrial cancer: incidence, prognostic factors, diagnosis, and treatment. Semin Oncol. 1997;24(1 Suppl 1):S1-140-S141-150.

14. DiSaia PJ, Creasman WT: Endometrial hyperplasia/estrogen therapy; in PJ DiSaia, WT Creasman (eds): Clinical Gynecologic Oncology. St Louis, MO, Mosby 1997, pp.111.

15. Trimble CL, Kauderer J, Zaino R, Silverberg S, Lim PC, Burke JJ, 2nd, Alberts D, et al. Concurrent endometrial carcinoma in women with a biopsy diagnosis of atypical endometrial hyperplasia: a Gynecologic Oncology Group study. Cancer. 2006;106(4):812-819.

16. Giede KC, Yen TW, Chibbar R, Pierson RA. Significance of concurrent endometrial cancer in women with a preoperative diagnosis of atypical endometrial hyperplasia. J Obstet Gynaecol Can. 2008;30(10):896-901.

17. Crissman JD, Azoury RS, Barnes AE, Schellhas HF. Endometrial carcinoma in women 40 years of age or younger. Obstet Gynecol. 1981;57(6):699-704.

18. World Medical Association. Declaration of Helsinki: Recommendations Guiding Physicians in Biomedical Research Involving Human Subjects. Seoul, Korea, 2008.

19. Montejo M, Werner TL, Gaffney D. Current challenges in clinical management of endometrial cancer. Adv Drug Deliv Rev. 2009;61(10):883-889.

20. Iram S, Musonda P, Ewies AA. Premenopausal bleeding: When should the endometrium be investigated?--A retrospective non-comparative study of 3006 women. Eur J Obstet Gynecol Reprod Biol. 2010;148(1):86-89. 